\title{
Comments on Ren et al.: Is duration of preoperative anti-tuberculosis treatment a risk factor for postoperative relapse or non-healing of spinal tuberculosis?
}

\author{
Fangfan $\mathrm{Ye}^{1,2} \cdot$ HaiBo $\mathrm{Li}^{3} \cdot \mathrm{Jia} \mathrm{Huang}^{4}$
}

Received: 18 March 2016/Accepted: 14 April 2016/Published online: 12 May 2016

(C) Springer-Verlag Berlin Heidelberg 2016

\section{Dear Editor,}

Ren et al. [1] report that lumbosacral and thoracolumbar junction have a higher recurrence rate of spinal tuberculosis (TB) via a retrospective follow-up study of 223 patients with spinal TB. This is not a random control trial. Therefore, patients status such as the presence or absence of chronic medical disease, age, drug-resistant TB, which could affect the final findings, should be considered fully.

Drug-resistant TB, especially multidrug-resistant and extensively drug-resistant $\mathrm{TB}$ is a major threat to the control of TB worldwide [2]. National survey of drug-resistant TB in China demonstrated that China has the world's largest number of patients with multidrug-resistant $\mathrm{TB}$, and primary transmission is responsible for most cases [3]. Drug resistance complicates efforts to control TB. Patients infected with organisms resistant to rifampin

A response to these comments can be found at doi:10.1007/s00586016-4572-7.

\section{Jia Huang}

huangjia10@csu.edu.cn

1 Department of Anesthesia, Hunan Provincial People's Hospital, The First Affiliated Hospital of Hunan Normal University, Changsha 410011, Hunan, People's Republic of China

2 The State Key Laboratory of Medical Genetics, School of Life Sciences, Central South University,

Changsha 410078, Hunan, People's Republic of China

3 Department of Ophthalmology, Xiangya Hospital, Central South University, Xiang Ya Road 87, Hunan Province Changsha, Changsha 410008, Hunan, China

4 Department of Critical Care Medicine, Second Xiangya Hospital, Central South University, 139 Renmin Road, Changsha 410011, People's Republic of China receive a high rate of therapy failure. Patients infected with organisms resistant to both isoniazid and rifampin need at least 18 months of treatment [4]. Thus, the authors should not ignore the effect of drug-resistant TB contributed to the spinal tuberculosis recurrence or relapse. We think it is necessary for the authors to supplement the mycobacterial drug sensitivity test or to give molecular detection of drug resistant tuberculosis, which could provide more evidence for spinal tuberculosis recurrence or relapse in this study.

Conflict of interest None.

\section{References}

1. Ren HL, Jiang JM, Wang JX, Qu DB, Chen JT (2016) Is duration of preoperative anti-tuberculosis treatment a risk factor for postoperative relapse or non-healing of spinal tuberculosis? Eur Spine J. doi:10.1007/s00586-016-4496-2

2. Nathanson E, Nunn P, Uplekar M, Floyd K, Jaramillo E, Lonnroth K, Weil D, Raviglione M (2010) MDR tuberculosis—critical steps for prevention and control. N Engl J Med 363:1050-1058. doi:10. 1056/NEJMra0908076

3. Zhao Y, Xu S, Wang L, Chin DP, Wang S, Jiang G, Xia H, Zhou Y, Li Q, Ou X, Pang Y, Song Y, Zhao B, Zhang H, He G, Guo J, Wang Y (2012) National survey of drug-resistant tuberculosis in China. N Engl J Med 366:2161-2170. doi:10.1056/ NEJMoa1 108789

4. Lange C, Abubakar I, Alffenaar J-WC, Bothamley G, Caminero JA, Carvalho ACC, Chang K-C, Codecasa L, Correia A, Crudu V (2014) Management of patients with multidrug-resistant/extensively drug-resistant tuberculosis in Europe: a TBNET consensus statement. Eur Respir J 44:23-63 